\title{
Insulin Secretion and Growth Failure in Uremia
}

\author{
ROBERT H. K. MAK \\ Division of Nephrology, Department of Pediatrics, Stanford University School of Medicine, \\ Stanford, California $94305-5719$
}

\begin{abstract}
Glucose and insulin metabolism was studied in 16 adolescents with uremia on hemodialysis. Glucose tolerance was measured by i.v. glucose tolerance tests (IVGTT). Insulin sensitivity was measured by the euglycemic clamp technique. Insulin secretion during constant hyperglycemia was measured by the hyperglycemic clamp technique. Controls consisted of eight healthy young adults. These patients could be further subdivided into two groups with respect to their growth velocity SD score (GVSDS). Group one consisted of eight patients with GVSDS more than -2 . This group had normal $1,25(\mathrm{OH})_{2} \mathrm{D}_{3}$ and demonstrated insulin resistance, hyperinsulinemia, and normal glu-

of insulin sensitivity in adolescents, both groups of patients on hemodialysis were still insulin resistant. The insulin secretion values in group one was similar to reported values for normal adolescents, whereas the values in group two were lower. GVSDS correlated significantly only with insulin secretion and not with glucose tolerance, insulin sensitivity, $1,25(\mathrm{OH})_{2} \mathrm{D}_{3}$, or PTH. Normal adolescents demonstrate an increase in insulin secretion as they go into puberty. It seems that the puberty growth spurt in adolescents both with normal health and renal failure may require increased insulin secretion as one of its hormonal requirements. (Pediatr Res 38: 379-383, 1995)
\end{abstract} cose tolerance when compared with adult controls. Group two consisted of eight patients with GVSDS less than -2 . This latter group had low $1,25(\mathrm{OH})_{2} \mathrm{D}_{3}$, insulin resistance, but normoinsulinemia and glucose intolerance compared with adult controls. Published data in the literature showed that normal pubertal adolescents demonstrated insulin resistance and hyperinsulinemia compared with normal adults. Compared with normal values

The presence of impaired glucose utilization in adults patients with end-stage renal disease has been recognized for over 80 y (1). This can present clinically as fasting hyperglycemia and hyperinsulinemia, abnormal glucose tolerance tests, decreased insulin secretion in response to glucose loads, and reduced peripheral sensitivity to insulin action $(1,2)$. Previous studies have demonstrated glucose intolerance and inhibition of insulin secretion in pediatric patients with preterminal chronic renal failure not on dialysis $(3,4)$. There is no published data on insulin sensitivity and insulin secretion in pediatric patients on hemodialysis. Furthermore, a recent report showed significant correlations between growth velocity and indices of insulin metabolism in young children and adolescents with preterminal chronic renal failure (5). The relationship between growth failure and insulin abnormalities has not been examined in pediatric patients on hemodialysis. The aim of the present study is to examine glucose tolerance, insulin sensitivity, and insulin secretion as well as their relationship

Received December 30, 1994; accepted March 29, 1995

Correspondence and reprint requests: Robert H. K. Mak, Division of Nephrology, Department of Pediatrics, Rm. G-306, Stanford University Medical Center, Stanford, CA 94305-5119.

$\quad$ Abbreviations
IVGTT, i.v. glucose tolerance test
GVSDS, growth velocity SD score
$\mathbf{1 , 2 5}(\mathbf{O H})_{2} \mathbf{D}_{\mathbf{3}}, 1,25$-dihydroxyvitamin $\mathrm{D}_{3}$
$\boldsymbol{K}$, glucose tolerance index during IVGTT

with growth velocity in adolescents with end stage renal disease on hemodialysis.

\section{METHODS}

Sixteen adolescents (aged 12-16 y) with end-stage renal disease were studied. All patients were pubertal with Tanner puberty stages between 2 and 4 . They were maintained on regular hemodialysis three times a week for at least 2 mo before the studies. Medications included oral $1,25(\mathrm{OH})_{2} \mathrm{D}_{3}$, calcium carbonate, sodium bicarbonate, and water-soluble vitamins (Nephro-vite; R\&D Labortabories, Inc., Marina Del Rey, $\mathrm{CA}) .1,25(\mathrm{OH})_{2} \mathrm{D}_{3}$ was discontinued $2 \mathrm{~d}$ before each study. Four patients from each group had previous renal transplants. They had not been noted to have hyperglycemia with corticosteroids after transplantation. None of the patients was on corticosteroids at the time or had been on corticosteroids for 12 mo before the study. Their daily intake of carbohydrate was more than $200 \mathrm{~g}$, and their weight was stable for at least 2 mo before the studies. Their dietary intakes of sodium $(2 \mathrm{~g} / \mathrm{d})$, potassium $(2 \mathrm{~g} / \mathrm{d})$, and phosphorus $(800 \mathrm{mg}$ ) were restricted. Dietary intakes were verified by a 3-d dietary recall every month and adjustments made if necessary. Height was measured with a Harpenden Stadiometer (Holtain Ltd. Crymych, 
Dyfel, UK) and growth velocity was calculated using height measurements in the twelve months before the study. Growth velocity was calculated from the height data over the previous year. GVSDS = (height velocity - mean height velocity for age)/SD of height velocity for age (6). All patients did not have history of or family history of diabetes mellitus. Controls consisted of eight young healthy adults (aged 18-25 y) consuming regular weight maintaining diets and taking no medications. They did not have history of any significant illness or any family history of diabetes mellitus. All patients and controls were within $20 \%$ of their ideal weight for height.

All studies were started approximately $0900 \mathrm{~h}$ after an overnight fast of approximately $10-12 \mathrm{~h}$ just before a scheduled hemodialysis session. The patients sat comfortably in a reclining chair and were not allowed to eat or drink apart from water during the studies. Glucose tolerance was measured by IVGTT. Two i.v. lines were started in contralateral arms. One i.v. line was used for blood sampling and was kept patent by a slow i.v. infusion of normal saline. The other i.v. line was used for infusion of glucose. After obtaining at least two serum samples for fasting glucose and insulin concentrations, a bolus of $50 \%$ dextrose $(0.5 \mathrm{~g} / \mathrm{kg})$ was given i.v. Thereafter blood samples were obtained for determination of serum glucose concentrations at $5,10,15,20,30,40,50,60,70,80$, and 90 min. $K$ values were measured using the formula: $K=0.693 / t$ $\times 100 \%$ where $t$ was the time taken for serum glucose concentrations to decline from the peak concentration to half the peak value (7).

Insulin sensitivity was measured by the euglycemic clamp technique (8). All patients had arteriovenous fistulas as access for hemodialysis. A dialysis needle was inserted into the arteriovenous fistula for blood sampling and used later for hemodialysis. This was kept patent by a slow normal saline infusion. In the normal controls, the sampling line was inserted in a vein on the dorsum of the hand. The hand was then placed in a heated box $\left(65^{\circ} \mathrm{C}\right)$ to arterialize the blood (9). An indwelling catheter was placed in a vein in the opposite arm for infusion of glucose and/or insulin. After obtaining at least three fasting serum samples for glucose and insulin concentration, a prime-continuous infusion of insulin was given i.v. to acutely raise and maintain the serum insulin concentrations at approximately $100 \mu \mathrm{U} / \mathrm{mL}$ above the basal level for $2 \mathrm{~h}$. The serum glucose concentration was measured at 10 -min intervals, and a variable infusion of $20 \%$ dextrose was adjusted to maintain the glucose concentration at fasting levels. Under these steadystate conditions of euglycemia, all of the infused glucose $\left(\mathrm{mg} / \mathrm{m}^{2} / \mathrm{min}\right)$ was taken up by cells and yielded a measure of the body's insulin sensitivity to the exogenously infused insulin. Because of the ethical issues of radioactivity administration in pediatric patients, tritiated glucose turnover studies to quantitate hepatic glucose uptake were not performed.

Insulin secretion was measured by the hyperglycemic clamp technique (8). Patient preparation was similar to the euglycemic clamp. A priming dose of $20 \%$ dextrose was given to acutely raise blood glucose concentration at $125 \mathrm{mg} / \mathrm{dL}$ above fasting glucose concentrations. Constant hyperglycemia at this level was then maintained for $120 \mathrm{~min}$ by varying the infusion of $20 \%$ dextrose and no exogenous insulin. Blood was taken every 10 min for measurement of serum insulin concentrations. The mean insulin concentration $(\mu \mathrm{U} / \mathrm{mL})$ from 20 to $120 \mathrm{~min}$ is an index of the insulin secretion in response to constant hyperglycemia.

Serum glucose concentration was measured by the glucose oxidase method using a Yellow Springs 23 AM glucose analyzer (Yellow Springs Instruments, Yellow Springs, OH). Serum immunoreactive insulin concentration was measured by double antibody RIA (Pharmacia, Uppsala, Sweden). Serum PTH was measured by an immunoradiometric assay for the intact molecule (Nichols, San Juan Capistrano, CA). Serum $1,25(\mathrm{OH})_{2} \mathrm{D}_{3}$ was measured by a radioreceptor assay $(\mathrm{Ni}-$ chols). This assay is specific for both $1,25(\mathrm{OH})_{2} \mathrm{D}_{3}$ and $1,25(\mathrm{OH})_{2} \mathrm{D}_{2}$. It involves a preliminary extraction and purification of serum using a single column containing a $\mathrm{C}_{18} \mathrm{OH}-$ activated matrix. Once purified, the material was quantitated in a radioreceptor assay using a calf thymus receptor and tritiated $1,25(\mathrm{OH})_{2} \mathrm{D}_{3}$. Separation of bound from free $1,25(\mathrm{OH})_{2} \mathrm{D}_{3}$ was achieved by incubation with dextran coated charcoal. Serum total calcium, phosphorus, potassium, magnesium, creatinine and blood urea nitrogen were measured by standard methods on a multichannel autoanalyzer.

The study was approved by the Committee for Clinical Investigations (Institutional Review Board) at Children's Hospital of Los Angeles. The Institutional Review Board did not allow studies in normal healthy adolescents. The purpose and potential risks of the study was carefully explained to all patients, parents, and subjects, and written informed consent was obtained before their participation. All values are expressed as mean \pm SEM. The data were tested for normality using the $\chi^{2}$ method. The least square method of linear regression and one-way analysis of variance were used for analysis of the results. Statistical significance was recognized at the 5\% level.

\section{RESULTS}

Constant euglycemia and hyperglycemia was achieved in all insulin clamp and glucose clamp studies, respectively. The mean intraassay coefficient of variation of serum glucose was $6.8 \pm 0.3 \%$ during the euglycemic clamp studies and $7.3 \pm$ $0.3 \%$ during the hyperglycemic clamp studies. The interassay coefficient of variation for glucose tolerance was $10.9 \%$ from five repeated studies in one normal subject. The interassay coefficient of variation for insulin sensitivity during the euglycemic clamp studies was $8.2 \%$ from five repeated studies performed monthly in the same normal subject. The interassay coefficient of variation for insulin secretion during the hyperglycemic clamp studies was $4.7 \%$ from five repeated studies performed monthly in another normal subject. The intraassay and interassay coefficients of variation of the insulin assay were 5.2 and $8.2 \%$, respectively. The intraassay and interassay coefficients of variation of the PTH assays were 7.2 and $9.3 \%$, respectively. The intraassay and interassay coefficient of variation of the $1,25(\mathrm{OH})_{2} \mathrm{D}_{3}$ assays were 8.2 and $9.9 \%$, respectively.

Mean GVSDS in the patients was $-1.6 \pm 0.5$. The patients can be divided into two groups according to the GVSDS. 
Group 1 had GVSDS more than -2 and the group 2 had GVSDS less than -2 . The clinical and biochemical data in these two groups of patients are presented in Table 1. Serum PTH were higher and serum $1,25(\mathrm{OH})_{2} \mathrm{D}_{3}$ were lower in the second group $(p<0.02)$. Serum PTH was high in both groups of patients, whereas serum $1,25(\mathrm{OH})_{2} \mathrm{D}_{3}$ was not different in group 1 and lower in group 2 when compared with control values. In other words, whereas both groups had evidence of hyperparathyroidism, group 1 demonstrated normal $1,25(\mathrm{OH})_{2} \mathrm{D}_{3}$ status, whereas group 2 demonstrated $1,25(\mathrm{OH})_{2} \mathrm{D}_{3}$ deficiency. Serum $1,25(\mathrm{OH})_{2} \mathrm{D}_{3}$ was lower than in group 2 than data in our laboratory in normal children. Group 1 had normal fasting glucose but fasting hyperinsulinemia, whereas group 2 had fasting hyperglycemia but normal fasting insulin concentrations. There were no significant differences in other biochemical parameters between the two groups. The indices of glucose metabolism in the two different groups of patients are presented in Figure 1. Glucose tolerance was normal in group $1(p<0.02)$ but was lower in group 2 compared with controls. Insulin sensitivity during the euglycemic clamp studies was lower in both groups compared with controls $(p<0.02)$. Insulin secretion was higher $(p<0.02)$ in group 1 but not different in group 2 compared with controls. GVSDS correlated with insulin secretion during the hyperglycemic clamp studies (Fig. $2 ; p<0.02$ ) but did not correlate with glucose tolerance, insulin sensitivity, PTH or $1,25(\mathrm{OH})_{2} \mathrm{D}_{3}$ concentrations.

\section{DISCUSSION}

The present study confirms the presence of abnormalities in glucose and insulin metabolism in uremic children. El-Bishti et al. (10) demonstrated glucose intolerance in children on hemodialysis using the IVGTT, but they did not study insulin sensitivity or secretion using glucose clamp methodologies. Studies in children with preterminal renal failure not on dial-

Table 1. Clinical data and serum biochemistry in hemodialysis

\begin{tabular}{lccc} 
& \multicolumn{3}{c}{ patients } \\
\hline Age $(\mathrm{y})$ & Group 1 & Group 2 & Controls \\
Sex $(\mathrm{M} / \mathrm{F})$ & $15 \pm 2^{*}$ & $16 \pm 2^{*}$ & $22 \pm 2$ \\
GVSDS & $5 / 3$ & $4 / 4$ & $4 / 4$ \\
$1,25(\mathrm{OH})_{2} \mathrm{D}_{3}$ & $-1.6 \pm 0.4 \dagger$ & $-2.7 \pm 0.3$ & \\
$\quad(\mathrm{pg} / \mathrm{mL})$ & $29 \pm 2 \dagger$ & $18 \pm 2^{*}$ & $35 \pm 3$ \\
$\mathrm{PTH}(\mathrm{pg} / \mathrm{mL})$ & & & \\
Glucose $(\mathrm{mg} / \mathrm{dL})$ & $132 \pm 38^{*} \dagger$ & $320 \pm 68^{*}$ & $18 \pm 2$ \\
Insulin $(\mu \mathrm{U} / \mathrm{mL})$ & $90+3 \dagger$ & $101+3^{*}$ & $88 \pm 3$ \\
Calcium $(\mathrm{mg} / \mathrm{dL})$ & $9.5 \pm 0.3$ & $12 \pm 1$ & $11 \pm 1$ \\
Phosphorus $(\mathrm{mg} / \mathrm{dL})$ & $6.8 \pm 0.7^{*}$ & $7.1 \pm 0.3$ & $9.7 \pm 0.4$ \\
Bicarbonate & $23 \pm 1$ & $23 \pm 1$ & $4.0 \pm 0.1$ \\
$\quad(\mathrm{mmol} / \mathrm{L})$ & & & $25 \pm 1$ \\
Creatinine $(\mathrm{mg} / \mathrm{dL})$ & $12.8 \pm 1.1^{*}$ & $13.0 \pm 1.0^{*}$ & $0.9 \pm 0.1$ \\
Urea nitrogen & $83 \pm 6^{*}$ & $80 \pm 7$ & $13 \pm 2$ \\
$\quad(\mathrm{mg} / \mathrm{dL})$ & & &
\end{tabular}

To convert to SI units: glucose, $\mathrm{mg} / \mathrm{dl} \times 0.055=\mathrm{mmol} / \mathrm{L}$; calcium, $\mathrm{mg} / \mathrm{dL}$ $\times 0.25=\mathrm{mmol} / \mathrm{L}$; phosphorus, $\mathrm{mg} / \mathrm{dL} \times 0.3229=\mathrm{mmol} / \mathrm{L}$; bicarbonate, same unit; Creatinine, $\mathrm{mg} / \mathrm{dL} \times 88.4=\mathrm{mmol} / \mathrm{L}$; and urea nitrogen $\mathrm{mg} / \mathrm{dL} \times$ $0.357=\mathrm{mmol} / \mathrm{L}$ of urea.

$* p<0.01$ vs control.

$\dagger p<0.01$ vs group 2 .
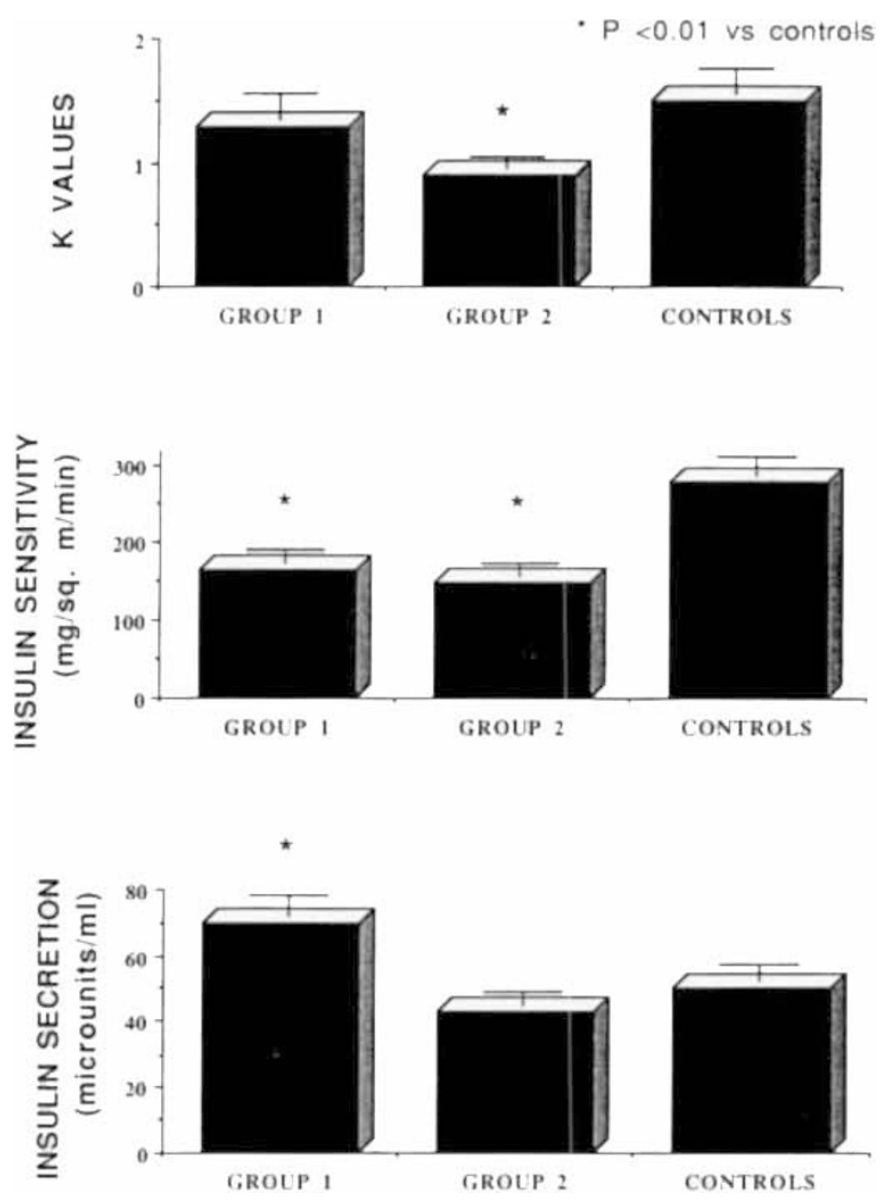

Figure 1. Glucose tolerance ( $K$ values during IVGTT); insulin sensitivity index ( $M$ during euglycemic clamps) and insulin secretion index (I during hyperglycemic clamps) in group 1 , group 2 , and controls.

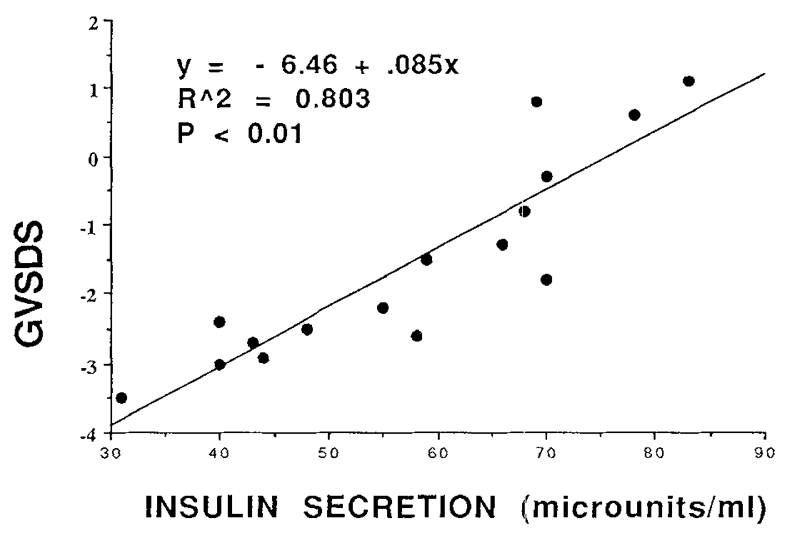

Figure 2. Correlation between growth velocity SD scores (GVSDS) and insulin secretion index (I) during hyperglycemic clamps in adolescents on hemodialysis.

ysis have previously demonstrated glucose intolerance and insulin resistance, but lack of an appropriate hyperinsulinemic response (4). This inhibition of insulin secretion in patients with chronic renal failure is likely to be secondary to $1,25(\mathrm{OH})_{2} \mathrm{D}_{3}$ deficiency rather than secondary hyperparathyroidism. Acute i.v. administration of $1,25(\mathrm{OH})_{2} \mathrm{D}_{3}$ to uremic patients on hemodialysis, withdrawn from $1,25(\mathrm{OH})_{2} \mathrm{D}_{3}$, led to a significant increase in insulin secretion and reversal of glucose intolerance (11). IVGTT performed in these hemodialysis 
patients after cessation of their normal maintenance dose of $1,25(\mathrm{OH})_{2} \mathrm{D}_{3}$ supplements for $3 \mathrm{~d}$ showed the presence of glucose intolerance. Acute i.v. $1,25(\mathrm{OH})_{2} \mathrm{D}_{3}, 2 \mathrm{~h}$ before glucose tolerance tests, led to correction of glucose intolerance. Insulin secretion during the hyperglycemic clamp technique showed significant increases during the vitamin $D$ replacement studies. These events occurred without any significant changes in PTH concentrations. These results are consistent with the hypothesis that $1,25(\mathrm{OH})_{2} \mathrm{D}_{3}$ deficiency contributes to the induction of glucose intolerance in uremia by inhibiting insulin secretion. This hypothesis is consistent with evidence of a cytosolic receptor protein for $1,25(\mathrm{OH})_{2} \mathrm{D}_{3}$ in the pancreatic $\beta$ cell (12) and that dietary vitamin $\mathrm{D}$ is essential for the normal physiologic regulation of insulin secretion (13). Vitamin D deficiency in rats with normal renal function inhibits insulin but not glucagon secretion (14) and induces glucose intolerance and hypoinsulinemia (15). Acute i.v. administration of $1,25(\mathrm{OH})_{2} \mathrm{D}_{3}$ increased insulin secretion and corrected glucose tolerance in vitamin $\mathrm{D}$-depleted animals (15). Furthermore, $1,25(\mathrm{OH})_{2} \mathrm{D}_{3}$ specifically, but no other vitamin $\mathrm{D}$ metabolite, seems to play an essential role in modulating insulin secretion (16).

In the present study, both groups of patients were insulinresistant. Group one, who demonstrated normal growth and normal serum $1,25(\mathrm{OH})_{2} \mathrm{D}_{3}$, were capable of increasing their insulin secretion and maintaining normal glucose tolerance; whereas group two, who demonstrated growth failure and $1,25(\mathrm{OH})_{2} \mathrm{D}_{3}$ deficiency, could not increase insulin secretion with resultant glucose intolerance. The control group is less than ideal with respect to insulin sensitivity and insulin secretion because normal adolescents are insulin-resistant and hyperinsulinemic compared with normal adults (17-19). Compared with published insulin sensitivity values in normal adolescents $\left(201 \pm 12 \mathrm{mg} / \mathrm{m}^{2} / \mathrm{min}\right)(15,16)$, both groups of patients (group 1, $165 \pm 17$; group 2,149 \pm 15 ) were still insulin-resistant. Compared with published insulin secretion values in normal adolescents $(68 \pm 8 \mu \mathrm{U} / \mathrm{mL})$ (19), insulin secretion was normal in group $1(70 \pm 6)$, whereas it was low in group $2(43 \pm 4)$. Thus, normal adolescents exhibit an increase in insulin secretion as they go into their puberty when they normally experience a growth spurt (19). Indeed, group one, that exhibited insulin secretion that was not different from normal adolescents, had relatively normal growth velocity. Group two, who exhibited insulin secretion lower than normal adolescents, had growth failure, as defined by GVSDS of less than -2 . GVSDS correlated significantly with insulin secretion but not with glucose tolerance, insulin sensitivity, $1,25(\mathrm{OH})_{2} \mathrm{D}_{3}$, or PTH. This is in agreement with recent data showing similar correlations in children with preterminal renal insufficiency not on dialysis (5). GVSDS correlated with insulin secretion measured during the hyperglycemic clamp study in predialysis adolescent children. Also, 13 children were followed longitudinally during medical suppression of hyperparathyroidism with dietary phosphate restriction and high dose phosphate binders. After effective suppression of hyperparathyroidism both GVSDS and insulin secretion increased significantly. The changes in GVSDS correlated well with the changes in insulin secretion but not with changes in PTH. It seems that the puberty growth spurt in adolescents both with normal health and renal failure may require increased insulin secretion as one of its hormonal requirements.

Insulin is an important hormone involved in the modulation of growth in health and disease (20). Children with type I diabetes mellitus are often growth-retarded. Rudolf et al. (21) reported an acceleration in linear growth in type I diabetic children when they were treated intensively with constant s.c. infusion of insulin. Milman et al. (22) showed that growth hormone and insulin but not growth hormone alone normalized nitrogen retention in diabetic rats. Costin et al. et al studied children with growth hormone deficiency after resection of crainiopharyngioma. Postoperative growth rates in these children correlated not with the growth hormone levels but rather with the peak insulin levels in response to oral glucose and i.v. tolbutamide (23). Salter and Best (24) treated hypophysectomized rats with insulin and observed a marked increase in body weight. These studies suggest that growth hormone may require the presence of insulin to implement its local target action of anabolism and growth promotion.

In summary, data in the present study demonstrated glucose intolerance and insulin resistance in adolescents on hemodialysis. Those patients, who were not $1,25(\mathrm{OH})_{2} \mathrm{D}_{3}$ deficient, could develop a hyperinsulinemic response and also had normal growth velocity. GVSDS correlated with insulin secretion, but not with insulin sensitivity, glucose tolerance, PTH, or $1,25(\mathrm{OH})_{2} \mathrm{D}_{3}$. Normal adolescents usually demonstrate an increase in insulin secretion as they go into puberty (19). The absence of this increase in insulin secretion in adolescents on hemodialysis with $1,25(\mathrm{OH})_{2} \mathrm{D}_{3}$ deficiency may be a significant factor in the pathogenesis of their growth failure. Hyperinsulinemia may be involved in the important mechanism of normal growth in children with or without renal failure. Further research should be directed at identifying the underlying mechanism.

Acknowledgments. The author thanks Stella Chang, M.S., and Joanne Wong, M.D., for assistance in the performance of the studies. He would also like to thank the nurses in the dialysis units at Children's Hospital of Los Angeles for their generous support and patience during the studies.

\section{REFERENCES}

1. DeFronzo RA, Andres R, Edgar P, Walker GW 1973 Carbohydrate metabolism in uremia: A review. Medicine 52:467-481

2. Mak RHK 1989 Carbohydrate metabolism in uremia. Pediatr Nephrol 3:201-208

3. Mak RHK, Haycock GB, Chantler C 1983 Glucose intolerance in children with chronic renal failure. Kidney Int 24(suppl 15):S22-S26

4. Mak RHK, Turner C, Haycock GB, Chantler C 1983 Secondary hyperparathyroidism and glucose intolerance in children with uremia. Kidney Int 24(suppl 16):S128-\$133

5. Mak RHK, Haycock GB, Chantler C 1994 Insulin and growth in chronic renal failure. Pediatr Nephrol 8:309-312

6. Tanner J 1986 Growth as a target-seeking function, catch up and catch down growth in man. In: Falkner, T. (ed) Human Growth. Plenum Press, New York, pp 167-179

7. Lundbaek K 1962 Intravenous glucose tolerance as a tool in definition and diagnosis of diabetes mellitus. Br Med J 1:1507:1513

8. DeFronzo RA, Tobin J, Andres R 1979 Glucose clamp technique: A method for quantifying insulin secretion and resistance Am J Physiol 237:E214-E223

9. McGuire EAH, Helderman JH, Tobin JD, Andres R, Berman M 1976 Effects of artcrial versus venous sampling on analysis of glucose kinctics in man. J Appl Physiol 41:565-573

10. El-Bishti MM, Counahan R, Bloom S, Chantler C 1978 Hormonal and metabolic responses to intravenous glucose in children on regular haemodialysis. Am J Clin Nutr 31:1865--1869 
11. Mak RHK 1992 1,25-Dihydroxycholecalciferol corrects glucosc intolerance in hemodialysis patients. Kidney Int 41:1049-1054

12. Pike JW 1981 Receptors for 1,25 -dihydroxyvitamin $D_{3}$ in chick pancreas: A partial physical and functional characterization. J Steroid Biochem 16:385-395

13. Kadowski S, Norman AW 1984 Dietary vitamin D is essential for normal insulin secretion from the perfused rat pancreas. J Clin Invest 73:759 766

14. Norman AW, Frankel BJ, Heldt AM, Grodsky GM 1980 Vitamin D deficiency inhibits pancreatic secretion of insulin. Science 209:823-825

15. Cade C, Norman AW 1987 Rapid normalization/stimulation by 1,25-dihydroxyvitamin $\mathrm{D}_{3}$ of insulin secretion and glucose tolerance in the vitamin $\mathrm{D}$ deficient rat. Endocrinology 120:1490-1497

16. Kadowski $\mathrm{S}$, Norman $\mathrm{AW} 1985$ Demonstration that the vitamin $\mathrm{D}_{3}$ metabolite $1: 25(\mathrm{OH})_{2}$ vitamin $D_{3}$ and not $24 R, 25(\mathrm{OH})_{2} \mathrm{D}_{3}$ is essential for normal insulin secretion in the perfused rat pancreas. Diabetes 34:315-321

17. Amiel SA, Sherwin RS, Simonson DC, Lauritano AA, Tamborlane WV 1986 Impaired insulin action in puberty: A contributing factor to poor glycemic control in adolescents with diabetes. N Engl J Med 315:215-219
18. Amiel SA, Caprio S, Sherwin RS, Plewe G, Haymond MW, Tamborlanc MV 1991 Insulin resistance of puberty: A defect restricted to peripheral glucose metabolism. J Clin Endocrinol Metab 72:277-282

19. Caprio S, Plel G, Diamond MP, Simonson DC, Boulware SD, Sherwin RS, Tambo rlane WV 1989 Increased insulin secretion in puberty: A compensatory response to reductions in insulin sensitivity. J Pediatr 114:963--967

20. Cheek DB, Graystone JE 1978 Insulin and growth hormone: Regulators of growth with particular reference to muscle Kidney Int 14:317-322

21. Rudolf MCJ, Sherwin RS, Markowitz R, Tamborlane WV 1982 Effect of intensive insulin treatment on linear growth in the young diabetic patient. J Pediatr 101:133137

22. Milman AE, Demoor $P$, Lukens FDW 1951 Relation of purified growth hormone and insulin in regulation of nitrogen balance Am J Physiol 166:354-363

23. Costin G, Kogut MD, Philips LS, Daughaday WH 1976 Craniopharyngioma: The role of insulin in promoting postoperative growth. J Clin Endocrinol Metab 42:370-379

24. Salter J, Best CH 1953 Insulin as a growth hormone. Br Med J 2: 353-356 